“C 2017 IEEE. Personal use of this material is permitted. Permission from IEEE must be obtained for all other uses, in any current or future media, including reprinting/republishing this material for advertising or promotional purposes, creating new collective works, for resale or redistribution to servers or lists, or reuse of any copyrighted component of this work in other works." 


\title{
A Comparative Fuel Analysis of a novel HEV with conventional vehicle
}

\author{
Mohamed Awadallah ${ }^{1}$, Peter Tawadros ${ }^{2}$, Paul Walker ${ }^{3}$, Nong Zhang ${ }^{4}$, James Tawadros ${ }^{5}$ \\ ${ }^{1}$ School of Electrical, Mechanical and Mechatronic Systems, University of Technology Sydney - UTS \\ Mohamed.M.Awadallah@student.uts.edu.au', eng.m.zakaria@gmail.com¹,Peter.Tawadros@uts.edu.au², \\ Paul.Walker@uts.edu.au ${ }^{3}$, Nong.Zhang@uts.edu.au ${ }^{4}$, James.Tawadros@uts.edu.au ${ }^{5}$
}

\begin{abstract}
Improvements in fuel economy have always been a dominating driver of vehicle engineering. With some exceptions, benefits attained from hybrid powertrains to transient power delivery has not been the emphasis of research and development efforts. Developing cities around the world would realise significant benefits from improvements to fuel economy, which is outlined in this research by assessing the benefits of a novel HEV architecture. These benefits are compared to a conventional ICEpowered vehicle equivalent, which has an advantage in terms lower upfront costs. The commercial success of HEV implementation, therefore, is determined by its price comparison to conventional vehicles and payback over a number of years of use. This becomes especially important in regions of low-middle income, where the market is much more price-sensitive. The fuel economy of a conventional vehicle and mild hybrid electric vehicle are compared in this paper. This analysis includes vehicle modelling and simulation. Fuel economy is assessed and referenced with standard drive cycles provided by the U.S Environmental Protection Agency. Results demonstrate the benefits of a lower ongoing cost for the HEV architecture.
\end{abstract}

Keywords-Fuel economy; Gear-shifting control; Manual transmission; Mild hybrid electric vehicle (MHEV); Powertrain; Torque gap filling;

\section{INTRODUCTION}

Researchers and OEM's all over the world are constantly working on developing novel and complex control methods of multi-modal hybrid powertrain architectures [1] along with repeatable improvements in vehicle efficiency by a thorough review. The dominating global markets of the US, Japan and Europe are primary buyers of ULEV (Ultra-Low Emissions Vehicle), SULEV (Super-ULEV) PZEV (Partial ZeroEmissions Vehicle), AT-PZEV (Advanced Technology PZEV) or ZEV (Zero-Emissions Vehicle) vehicles and see their direct benefit. Many of the 35 member countries of the Organisation for Economic Co-operation and Development (OECD) have observed atmospheric pollutant level reductions since 2005 [2]. In saying this, developed regions like these have been able to reduce the respective impact on global air pollution through driving emissions standards and change energy production methods. This research aims to look at the development of a prototype vehicle which would provide the fuel-saving benefits of a hybrid vehicle architecture compared to a comparable baseline conventional vehicle with costeffective implementation for developing markets [3]. The baseline conventional vehicle chosen for this research is a 1990 year model Mazda MX-5. The vehicle was chosen for its structural simplicity, ubiquitous availability, and similarity to the average passenger vehicle fleet in many developing regions, which often have high average fleet age, and are heavily skewed toward B- and C-segment (lightweight) vehicles with older engine management systems. The hybrid vehicle architecture will be developed around the conventional MX-5 powertrain, and will include a supervisory controller, output-shaft mounted electric motor, and associated power electronics. We will discuss electric motor size optimisation, with a leaning on improving fuel economy, drive performance and overall efficiency by effective hybridization [4]. The opportunity for improvement in driving comfort, shifting quality, fuel economy, driveability and manufacturing costs are seen in the mild hybrid electric powertrain architecture [5]. A low-power electric motor mounted on the transmission output shaft, coupled to a controlled power source is representative of such an architecture allowing for increased functionality of the powertrain along with a reduction in the torque hole during gear changes. High-quality shift control proves essential to reducing torque hole and vibration of the powertrain, enhancing driving performance.

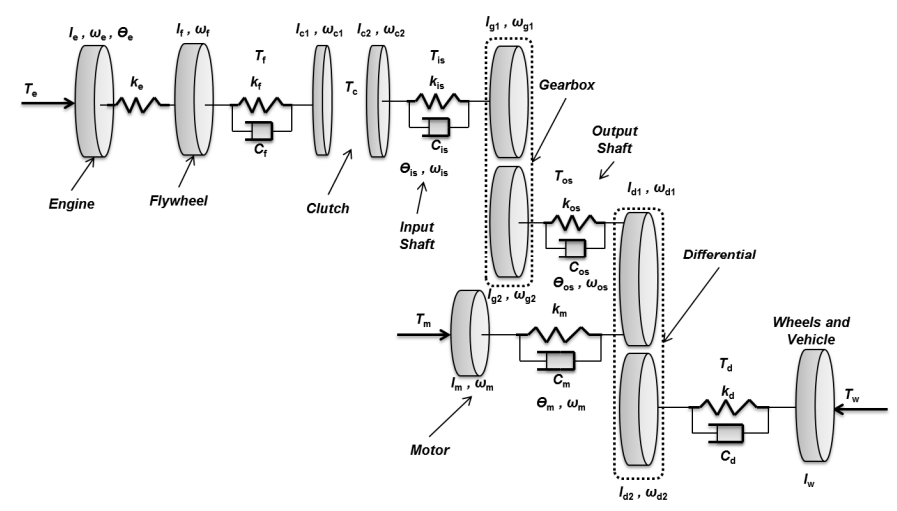

Fig. 1. Overall powertrain structure of the mild HEV model.

Parameters defined in Table IV and Table V

Previous papers have looked at the dynamics and limitations of modelling mild hybrid electric powertrains [6, 7]. Prior work conducted as part of our programme concluded that the most appropriate electric motor for this application is a low-cost HEV is a Brushless DC Motor (BLDC), with a rated continuous mechanical power output of $10 \mathrm{~kW}(30 \mathrm{~kW}$ peak) [8]. The peak mechanical power figure is a significant consideration as the continuous output in this research, as the intended usage profile involves short pulses of high power for torque-filling. Extensive use of BLDC drive is seen in EV and HEV applications [9]. A $10 \mathrm{~kW}$ electric machine proved adequate for torque-fill during a gear change, with enough 
power for an observable improvement in vehicle efficiency, both under high demand or low engine efficiency conditions [10]. A simple post-transmission parallel hybrid configuration defines the powertrain. A low-powered four-cylinder engine is coupled to a five-speed manual transmission through a robotically actuated clutch. A motor is connected to the transmission output shaft before the final drive. Comparable architectures are observed in existing research [11, 12]. The scope of this research is modelled around the implementation of hybrid technology in developing markets, with a goal of reducing atmospheric pollutants in a cost effective manner. A schematic representation of the mild powertrain as illustrated in Fig. 1 will be used for comparison with a conventional vehicle equivalent (i.e. same architecture but without the electric motor and associated ancillaries). The size and capacity of each vehicle component will be analysed to meet desired outcomes. These elements include the driver, the battery, EM, vehicle, ICE, and transmission.

This paper will investigate the costs and consumptions associated with the driving usage of the proposed mild hybrid architecture. In Section II the costs associated with petrol and electric power consumption are investigated, and the additional costs associated with the prototype powertrain architecture are detailed. Following this Section III details the simulation strategy for the mild hybrid powertrain and demonstrates qualitatively the consistency of simulation results with other publically available data. In Section IV the impact on energy consumption is evaluated, and finally, in Section V the paper is summarised, and conclusions of the research are drawn.

\section{PRoduction Cost AnALYSIS}

Approximately $70 \%$ of global petrol consumption is due to transportation, with an expected increase of $50 \%$ between 2009 to 2030 [13]. With this in mind, a proof of concept exercise will look at the development of a low-cost electric hybrid drive system for small vehicles. The design of such will be mainly aimed at developing markets with which there is a direct relation to increased environmental pollutant levels [14]. An approach toward improving drive characteristics, specifically shift characteristics, of an automatic vehicle with low-cost hardware, will be taken in the development of a hybrid vehicle. It has been determined by the authors that a $5 \%$ cost limit on the net manufacturing cost increase of the base vehicle is representative of a realistic cost that would be deemed satisfactory by end users. As such, this costing has been included as a defining benchmark to cover the total cost of hybridization, including motor, inverter and battery in this paper. It must be noted that the accurate cost of manufacturing is hard to determine without final designs. McKeever [15] Hadley [16] Wu [17] offer ways of estimating these figures by looking at the cost of components determined by physical performance requirements. Utilising their methods, a 2016 figure of $\$ 31.30$ was determined per $\mathrm{kW}$ of electric power for the cost of a motor and controller. At this value, these two components would add approximately $\$ 375.60$ to the cost of the base vehicle. A cost approximation for a $1.2 \mathrm{kWh} \mathrm{NiMH}$ battery was determined to be $\$ 60$. Further reductions in cost can be affected by usage of a smaller battery pack [18]. The cumulative cost of the motor, controller and battery results in an overall additional cost of $\$ 435.60$. The cost of producing a simple B-segment vehicle varies depending on the specification and production region, however typically falls between $\$ 8000-\$ 12000$. In this case, the overall additional cost fulfils the goal of providing a system with the low-cost implementation of mild hybrid vehicle benefits. Suitability for mass-market vehicles sold in pre-mature stage markets is taken into consideration, with the aim of reducing atmospheric particle pollutants in urban regions [19]. However, more research and focus is required in the reducing costs further to make this goal feasible.

\section{SHIFT CONTROL STRATEGY}

By developing and validating publicly available legislated drive cycle data in simulation for the chosen vehicle for this study, a simulation strategy can be created to estimate fuel consumption for the alternative powertrain model we propose. This presents an opportunity for meaningful implementation in urban environments, where fuel consumption is up to $50 \%$ higher when compared to highway driving [20]. Discussed in this paper is a mild HEV powertrain model built in the Matlab/Simulink environment. More specifically, there is an emphasis on the electric drive mode part in the results. The transient response of the drivetrains is also compared. The different gear ratios of initial and target gear along with the throttle angle during the gear change determines the difference of the speed of the input shaft (in other words, engine speed). A large hole in the output torque coupled with a decrease in speed is seen as a consequence of the gear selection process. Referring to Fig. 2, by making sure that the motor is in contact with the final drive and that the clutch pressure remains applied throughout the shift-control process, a reduction in the torque hole can be achieved.

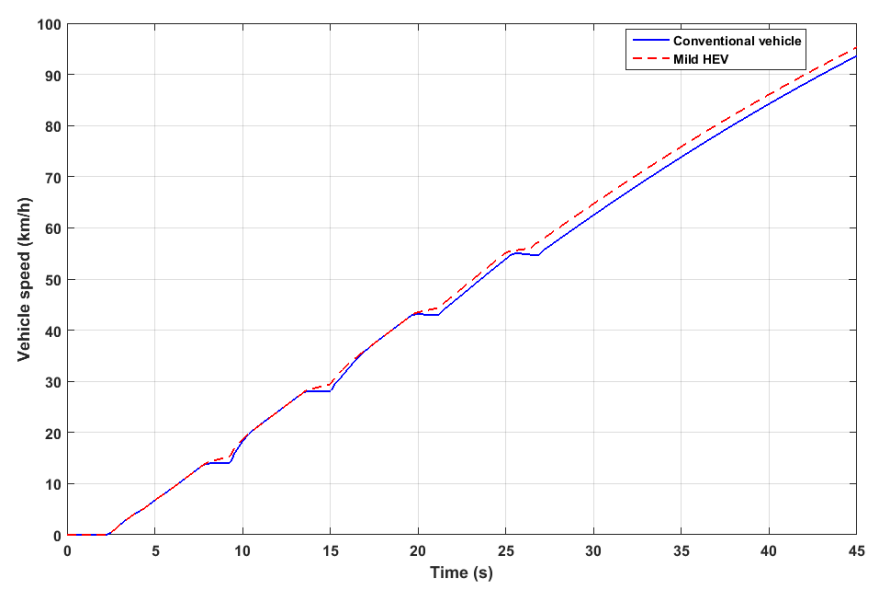

Fig. 2. Wheel Speed as a function of time.

The shift-control strategy utilises a supervisory controller which is master to the engine control module (slave 1) and the motor controller (slave 2). The supervisory controller passes control to slave 1 under most driving conditions, taking control during gear shifting events or during hybrid operation. During the gear shift event, the supervisory controller is responsible for the actuation and detection of clutch and gear position, prediction of torque demand at the end of the gear change event, and synchronizing engine and motor torque to 
minimise the torque hole. To execute this function the controller synchronises the load increase of the electric motor with the load decrease of the engine, disengaging the clutch at the optimum time, such that the torque removed by clutch disengagement is immediately compensated by the EM. At the time the clutch is fully disengaged, the mechanical gear selection is accomplished, and the throttle, electric power, and clutch engagement are modulated synchronously so as to minimise the step change in torque. A comparative analysis of conventional and torque-fill drivetrain simulation models was undertaken. [21].

\section{A. Simulation Strategy}

As a precursor to prototype development, the design cycle of hybrid vehicles can be made significantly cheaper and faster by utilising computer modelling and simulation. For the comparison, the modelling environment used was ADVISOR [22]. Other options include Autonomie and PSAT, however ADVISOR is readily accessible to the researchers, and has been developed and validated at the American National Renewable Energy Laboratory (NREL). Utilising a look-up table of fuel rate against engine operating point (defined by engine speed and torque), fuel use can be determined. Table VI in the appendix provides key specifications used by the baseline conventional vehicle. The fuel usage map as a function of operating point is based on a modified version of the map provided by ADVISOR. By taking an analogous method, an ADVISOR model with components similar to conventional model specifications was slightly adapted to match specifications of available power, fuel economy and emissions at the source pipe.

Both the New European Drive Cycle (NEDC), and New York Drive Cycle (NYC) were used for simulations. Drive cycles such as these are a standardised test regimen that allows direct comparison of fuel economy and emissions performance between vehicles. The NEDC and NYCC profiles are shown in Fig. 3 to Fig. 6. These cycles respectively comprise of a duration of 1185 and 598 Secs, a range of $10.8 \mathrm{~km}$ and 1.879 $\mathrm{km}$ with an average speed of $31 \mathrm{~km} / \mathrm{h}$ for both [23].

The NEDC was utilised primarily to provide a better comparison with the literature, as it is a widespread and wellunderstood standard. However, the NYC was also selected owing to its low average speed and frequent stops, which are representative of the typical urban driving conditions that were being replicated for our study. As there is an emphasis on the potential to improve global fuel economy characteristics, no considerations have been made to highway cycles as they do not represent an accurate illustration of global fuel consumption. The result of this can be seen in the observable values of enhanced fuel economy with mild hybrid configuration implementation, with a significantly smaller improvement in highway cycles than city driving. The simulated fuel consumption over the cycles respectively was $7.84 \mathrm{~L} / 100 \mathrm{~km}$ and $18.69 \mathrm{~L} / 100 \mathrm{~km}$. These values present a similar value to the documented consumptions of $8 \mathrm{~L} / 100 \mathrm{~km}$ and $18.8 \mathrm{~L} / 100 \mathrm{~km}$ respectively. As a consequence of these values, it can be safely concluded that the simulation model proves accurate enough for financial analysis further outlined in this research. This driving pattern is representing the driving condition in a suburb area, which has less idle times and includes high-speed cruising.

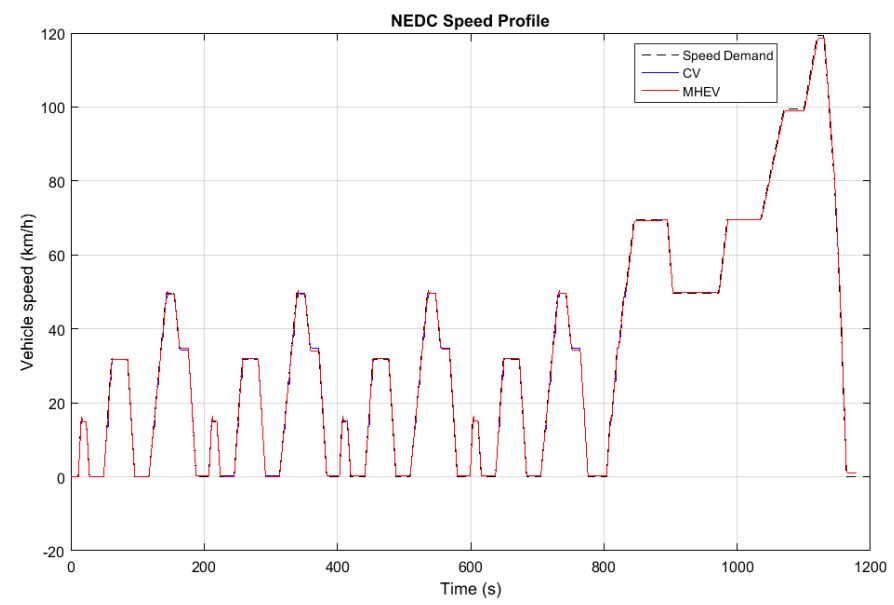

Fig. 3. The speed profile of the NEDC drive cycle.

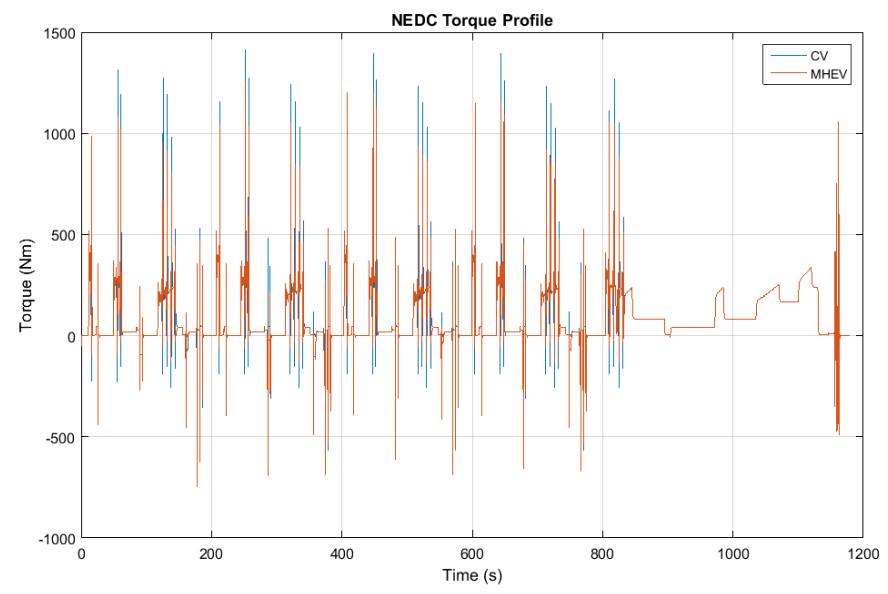

Fig. 4. The torque profile of the NEDC drive cycle.

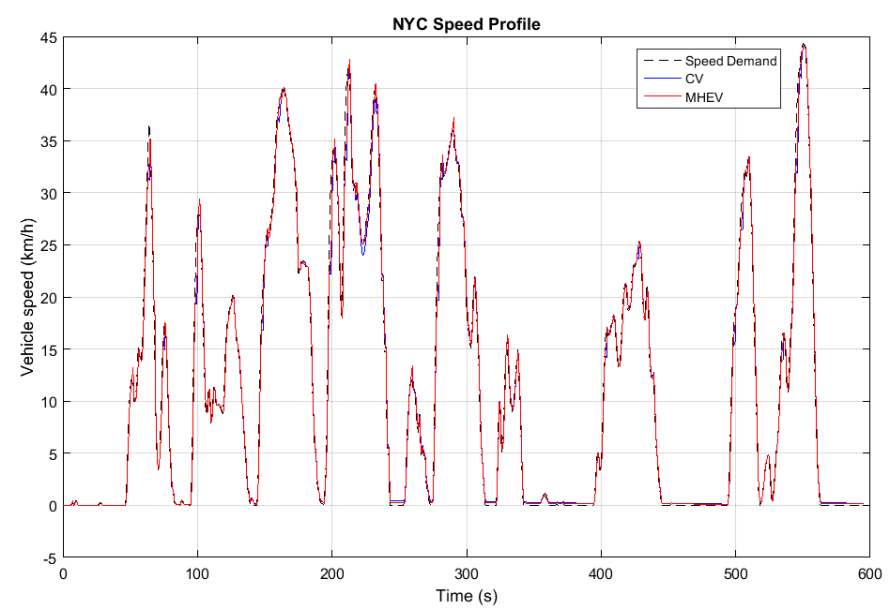

Fig. 5. The speed profile of the NYC drive cycle. 


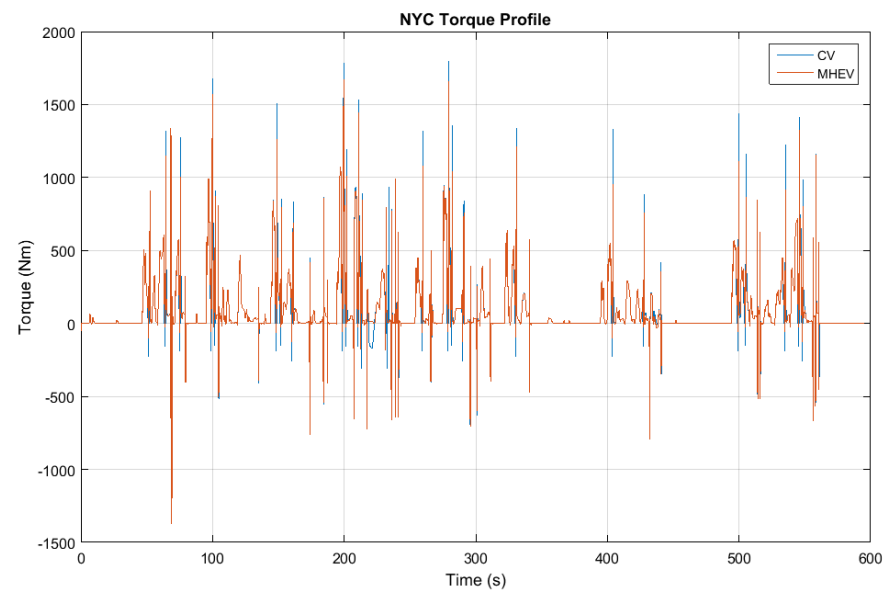

Fig. 6. The torque profile of the NYC drive cycle

\section{B. State of charge}

The SOC provides the information of the current, i.e., the amount of energy stored in the battery pack to the energy management controller (EMC), which will determine the drive mode suitable for the present driving conditions. The SOC calculation block calculates the SOC, or the residual capacity in units of ampere-hours, that remains available for discharge from the battery [24]. Note that the columbic efficiency and the maximum capacity are functions of temperature. The SOC can be calculated by (1). The SOC under different driving cycles are shown in Fig. 7. The simulation begins with the initial SOC of 0.9 .

$$
\text { SOC }=\left(1-\frac{\int_{0}^{\text {time }(s)} \operatorname{Current}(A)}{3600 \times \text { Battery Maximum Capacity }(A h)}\right) \times 100 \%
$$

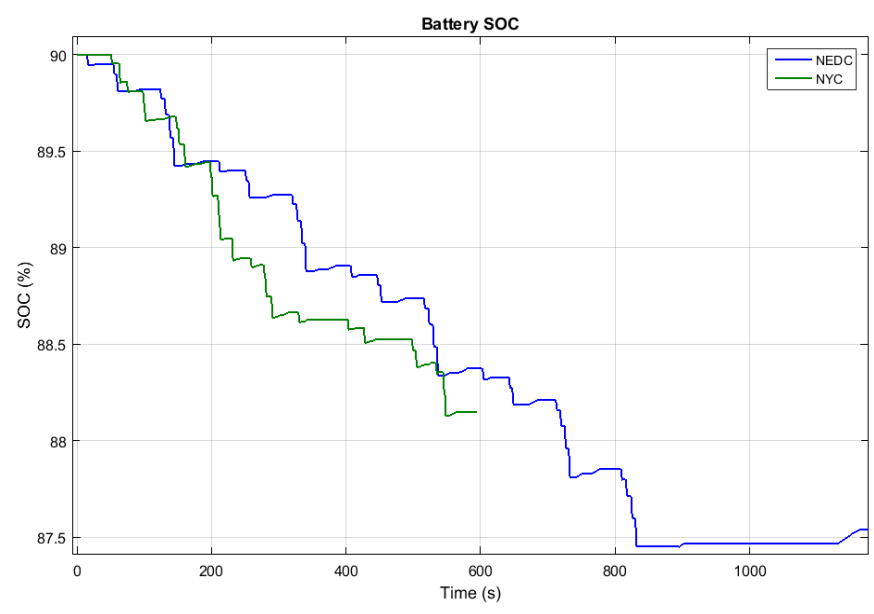

Fig. 7. Battery SOC of the NYC drive cycle.

\section{ANALYSIS OF FUEL ECONOMY AND ELECTRICITY CONSUMPTION}

The fuel and grid electricity consumption for each vehicle configuration developed are readily observed below. The energy consumption for the urban legislative cycles, NEDC and NYC, have been provided for comparison. The 'stop-start' behaviour of traffic flow proved to be a major contributor influencing fuel consumption in urban regions [25], with resulting values outlined in Table I. The difference in fuel economy improvements between drive cycles is apparent. An improvement of approximately $5 \%$ is seen with the use of mild hybrid drivetrains when compared to a conventional drivetrain. This is dependent upon the drive cycle and vehicle shift schedule used. For instance, a more aggressive shift schedule (such as might be typical of driver behaviour in an NYC-like setting) demonstrates comparatively worse results when compared to the same drive cycle against a conservative schedule setting.

Table I. Fuel economics for conventional and Mild HEV.

\begin{tabular}{|c|c|c|c|c|}
\hline \multirow[b]{2}{*}{$\begin{array}{l}\text { Drive } \\
\text { cycle }\end{array}$} & \multicolumn{2}{|c|}{ Fuel Economy (L/100 km) } & \multirow[b]{2}{*}{$\begin{array}{c}\text { Improvement } \\
\text { with hybrid } \\
(\%)\end{array}$} & \multirow{2}{*}{$\begin{array}{c}\text { Operating } \\
\text { Cost } \\
\text { Improvement } \\
(\$ 1.50 / \mathrm{L})\end{array}$} \\
\hline & $\begin{array}{c}\text { Conventional } \\
\text { drivetrain }\end{array}$ & $\begin{array}{c}\text { Mild } \\
\text { Hybrid } \\
\text { drivetrain }\end{array}$ & & \\
\hline NEDC & 8.3 & 7.9 & 4.8 & 0.6 \\
\hline NYC & 19.8 & 18.8 & 5.1 & 1.5 \\
\hline
\end{tabular}

Table II. Comparison chart for all vehicles tested Fuel and electricity consumption of the modelled vehicles.

\begin{tabular}{|c|c|c|c|c|c|c|}
\hline \multirow{4}{*}{ Vehicle } & \multicolumn{3}{|c|}{ NEDC } & \multicolumn{3}{|c|}{ NYC } \\
\cline { 2 - 7 } & $\begin{array}{c}\text { Fuel } \\
\text { Economy } \\
(\mathbf{L} / \mathbf{1 0 0} \\
\boldsymbol{k m})\end{array}$ & $\begin{array}{c}\text { Fuel } \\
\text { Consumption. } \\
\boldsymbol{L}\end{array}$ & $\boldsymbol{A h}$ & $\begin{array}{c}\text { Fuel } \\
\text { Economy } \\
(\mathbf{L} / \mathbf{1 0 0} \\
\boldsymbol{k m})\end{array}$ & $\begin{array}{c}\text { Fuel } \\
\text { Consum. } \\
\boldsymbol{L}\end{array}$ & Ah \\
\hline CV & 8.3 & 0.849 & - & 19.8 & 2.283 & - \\
\hline $\begin{array}{c}\text { Mild } \\
\text { HEV }\end{array}$ & 7.9 & 0.810 & 0.9 & 18.8 & 1.879 & 0.7 \\
\hline
\end{tabular}

The torque-fill system is not predominantly responsible for a fuel-economy benefit. However, by reducing the time taken to achieve cruising speed, enhanced fuel economy is a resulting consequence. The analysis of such an improvement was achieved by comparing the torque-fill drivetrain with the conventional ICE-only powertrain (shown in Fig. 2.). Quantitative values for the respective improvements in fuel economy are represented in Table III. When using the torquefill drivetrain, a slight improvement of approximately $4.16 \%$ in fuel economy over the conventional powertrain is observed. The velocity of the vehicle during an acceleration event $0-100$ $\mathrm{km} / \mathrm{h}$ is visible in Fig. 2 . The acceleration time is reduced by approximately 2.5 seconds. The use of torque-fill drivetrain reduces acceleration time by about 2.5 seconds, with a significant decrease in deceleration at each gear shift.

Table III. Comparison chart for all vehicles tested through the acceleration event $0-100 \mathrm{~km} / \mathrm{h}$

\begin{tabular}{|c|c|c|}
\hline Vehicle Model & $\begin{array}{c}\text { Distance Travelled } \\
\mathbf{~ k m} / \mathbf{L}\end{array}$ & $\begin{array}{c}\text { Fuel Economy } \\
\mathbf{L} / \mathbf{1 0 0} \mathbf{~ k m}\end{array}$ \\
\hline Conventional & 12.98 & 7.702 \\
\hline Mild HEV & 13.54 & 7.381 \\
\hline
\end{tabular}

From the simulation output, it can be concluded that the mild HEV powertrain plays a noteworthy role in enhancing fuel economy. Finally, with the results in Table I and the estimated cost of additional electronics, it is possible to estimate the driving distance required before payback is achieved. The operating cost is based on a weighted average of $40 \%$ NEDC 
and $60 \%$ NYC cycles. A cost of $\$ 1.50$ per litre of petrol is used for this analysis [26]. If the additional component cost is divided by the net cost of fuel consumption for the vehicle, the estimated driving distance for payback to be achieved is determined as $65,338 \mathrm{~km}$. This represents payback in approximately 4.3 years on a $15000 \mathrm{~km}$ annual distance travelled.

\section{CONCLUSION}

The research presented aims to improve driveability and comfort by the reduction of torque holes during shifts. This can be implemented by the use of a mild hybrid powertrain for a manual transmission vehicle. Both automated and traditional manual gearboxes see the successful implementation of the torque-fill drivetrain. The cost and size of other system components such as batteries and converters are constrained by both the motor power and duty cycle. Operation exceeding the rated continuous output of the components is possible due to the intermittent operation of the components, providing an improved observable result.

Values attained for both NEDC and NYC drive cycles fall within a predicted systemic pattern of behaviour. A realistic approach is taken to the size of the components of the vehicle subsystems, with the resultant performance output given by the desired capability goals. By taking into consideration earlier discussions and the resulting output based on discussed implementations, the use of MHEV as proposed is feasible and shows great potential. There is an observable improvement in fuel economy for the drive cycles, shown in the values yielded. By using one EM to reduce overall weight and cost, MHEV achieves desired performance with a more simplified structure. Therefore, implementation of the MHEV configuration is seen to be of great benefit. Future research at the University of Technology Sydney will further develop, implement, validate and report on these control strategies in experimental facilities.

\section{APPENDIX}

TABLE IV. MODEL PARAMETERS

\begin{tabular}{|c|c|c|}
\hline Name & Symbol & Units \\
\hline Torque & $\boldsymbol{T}$ & $\mathrm{Nm}$ \\
\hline Equivalent Inertia & $\boldsymbol{I}$ & $\mathrm{Kg} \mathrm{m}^{2}$ \\
\hline Speed & $\boldsymbol{\omega}$ & $\mathrm{rad} / \mathrm{s}$ \\
\hline Displacement & $\boldsymbol{\theta}$ & $\mathrm{rad}$ \\
\hline Torsional stiffness & $\boldsymbol{K}$ & $\mathrm{Nm} / \mathrm{rad}$ \\
\hline Friction Coefficient & $\boldsymbol{C}$ & $\mathrm{Nms} / \mathrm{rad}$ \\
\hline
\end{tabular}

TABLE V. ABBREVIATIONS

\begin{tabular}{|c|c|}
\hline Component & Symbol \\
\hline Engine & $e$ \\
\hline Flywheel & $F$ \\
\hline Clutch drum & $C l$ \\
\hline Clutch hub & $C 2$ \\
\hline Input Shaft & $i s$ \\
\hline Gearbox & $g$ \\
\hline Output shaft & $o s$ \\
\hline
\end{tabular}

Table VI. Vehicle Global Specifications

\begin{tabular}{|c|c|c|}
\hline Component & Parameter & SI Units \\
\hline \multirow{7}{*}{ Vehicle } & Mass as hybrid & $1200 \mathrm{~kg}$ \\
\hline & Frontal area & $3 \mathrm{~m}^{2}$ \\
\hline & Drag coefficient & 0.4 \\
\hline & Distance from CG to front axle & $1.4 \mathrm{~m}$ \\
\hline & Distance from CG to rear axle & $1.6 \mathrm{~m}$ \\
\hline & CG height & $0.5 \mathrm{~m}$ \\
\hline & Tire rolling radius & $0.312 \mathrm{~m}$ \\
\hline \multirow{6}{*}{ Engine } & Type & Spark-Ignition \\
\hline & Maximum power & $70 \mathrm{~kW}$ \\
\hline & Speed at maximum power & $5500 \mathrm{rpm}$ \\
\hline & Maximum speed & $7000 \mathrm{rpm}$ \\
\hline & Idling speed & $800 \mathrm{rpm}$ \\
\hline & Cylinders & 4 \\
\hline \multirow{6}{*}{ Gear ratio } & First & 3.581 \\
\hline & Second & 2.022 \\
\hline & Third & 1.4 \\
\hline & Fourth & 1.03 \\
\hline & Fifth & 0.94 \\
\hline & Final drive ratio & 4.06 \\
\hline \multirow{3}{*}{ Motor } & Voltage & $96 \mathrm{~V}$ \\
\hline & Maximum power output & $10 \mathrm{~kW}$ \\
\hline & Maximum torque & $54 \mathrm{Nm}$ \\
\hline \multirow{3}{*}{ Battery } & Type & $\mathrm{NiMH}$ \\
\hline & Capacity & $1.2 \mathrm{kWh} / 12.5 \mathrm{Ah}$ \\
\hline & Discharge/Charge rate & $15 \mathrm{C} / 10 \mathrm{C}$ \\
\hline
\end{tabular}

\section{REFERENCES}

S.-i. Jeon, S.-t. Jo, Y.-i. Park, and J.-m. Lee, "Multi-Mode Driving Control of a Parallel Hybrid Electric Vehicle Using Driving Pattern Recognition," Journal of Dynamic Systems, Measurement, and Control, vol. 124, pp. 141-149, 2000.

OECD, The Cost of Air Pollution: OECD Publishing, 2014.

B. Bilgin, P. Magne, P. Malysz, Y. Yang, V. Pantelic, M. Preindl, et al., "Making the case for electrified transportation," IEEE Transactions on Transportation Electrification, vol. 1, pp. 4-17, 2015.

C. Chan, "The state of the art of electric and hybrid vehicles," Proceedings of the IEEE, vol. 90, pp. 247-275, 2002.

T. S. Kim, C. Manzie, and H. Watson, "Fuel economy benefits of look-ahead capability in a mild hybrid configuration," IFAC Proceedings Volumes, vol. 41, pp. 5646-5651, 2008.

M. Awadallah, P. Tawadros, P. Walker, and N. Zhang, "Eliminating the torque hole: Using a mild hybrid EV architecture to deliver better driveability," in 2016 IEEE Transportation Electrification Conference and Expo, Asia-Pacific (ITEC AsiaPacific), Busan, South Korea, 2016, pp. 173-179.

M. Awadallah, P. Tawadros, P. Walker, and N. Zhang, "Comparative System Dynamic Modeling of a Conventional and Hybrid Electric Powertrain," in Power Engineering - International conference on Power Transmissions (ICPT 2016), Y. S. Datong Qin, Ed., ed Chongqing, China: CRC Press, 2016, pp. 231-238.

M. Awadallah, P. Tawadros, and N. Zhang, "Rapid Prototyping and Validation of Mars 0913 Brushless Motor to Develop Mild HEV," in The 7th TM Symposium China (TMC2015), Shanghai, China, 2015, pp. 92-98.

M. Zeraoulia, M. E. H. Benbouzid, and D. Diallo, "Electric motor drive selection issues for HEV propulsion systems: A comparative study," Vehicular Technology, IEEE Transactions on, vol. 55, pp. 1756-1764, 2006.

U. Wagner and A. Wagner, "Electrical shift gearbox (esg)consistent development of the dual clutch transmission to a mild hybrid system," SAE Technical Paper 0148-7191, 2005.

R. Baraszu and S. Cikanek, "Torque fill-in for an automated shift manual transmission in a parallel hybrid electric vehicle," in American Control Conference, 2002. Proceedings of the 2002, 2002, pp. 1431-1436. 
[12] K. Aoki, S. Kuroda, S. Kajiwara, H. Sato, and Y. Yamamoto, "Development of integrated motor assist hybrid system: development of the'insight', a personal hybrid coupe," Honda R and D Co., Ltd.(US)2000.

[13] A. MacKnight, "Engine an Innovation that Brings Improved Fuel Economy and a Reduced Carbon Foot print for Automotive Applications," presented at the PRESENTED AT THE CLINTON GLOBAL INITIATIVE ANNUAL GENERAL MEETING, New York, USA: RegTech, 2009.

[14] D. Campbell-Lendrum and C. Corvalán, "Climate change and developing-country cities: implications for environmental health and equity," Journal of Urban Health, vol. 84, pp. 109-117, 2007.

[15] J. W. McKeever, S. Das, L. M. Tolbert, L. D. Marlino, and A. Nedungadi, "Life-Cycle Cost Sensitivity to Battery-Pack Voltage of an HEV," Life, vol. 1, p. 1556, 2000.

[16] S. W. Hadley and T. P. Cleary, "Plug-in Hybrid Electric Vehicle Value Proposition Study-Final Report," 2010

[17] G. Wu, A. Inderbitzin, and C. Bening, "Total cost of ownership of electric vehicles compared to conventional vehicles: A probabilistic analysis and projection across market segments," Energy Policy, vol. 80, pp. 196-214, 2015.

[18] R. Sharma, M. Bessede, C. Manzie, M. Brear, and R. Crawford, "An economic and in-service emissions analysis of conventional, hybrid and electric vehicles for Australian driving conditions," SAE Int. J. Commer. Veh, vol. 5, pp. 291-298, 2012.

[19] T. Hutchinson, S. Burgess, and G. Herrmann, "Current hybridelectric powertrain architectures: Applying empirical design data to life cycle assessment and whole-life cost analysis," Applied Energy, vol. 119, pp. 314-329, 2014.

[20] R. Sharma, C. Manzie, M. Bessede, M. Brear, and R. Crawford, "Conventional, hybrid and electric vehicles for Australian driving conditions-Part 1: Technical and financial analysis," Transportation Research Part C: Emerging Technologies, vol. 25, pp. 238-249, 2012.

[21] K. L. Butler, M. Ehsani, and P. Kamath, "A Matlab-based modeling and simulation package for electric and hybrid electric vehicle design," IEEE Transactions on vehicular technology, vol. 48, pp. 1770-1778, 1999.

[22] A. C. Baisden and A. Emadi, "ADVISOR-based model of a battery and an ultra-capacitor energy source for hybrid electric vehicles," IEEE Transactions on Vehicular Technology, vol. 53, pp. 199-205, 2004.

[23] Z. Wei, J. Xu, and D. Halim, "HEV power management control strategy for urban driving," Applied Energy, 2016.

[24] A. R. Salisa, N. Zhang, and J. Zhu, "A comparative analysis of fuel economy and emissions between a conventional HEV and the UTS PHEV," IEEE Transactions on Vehicular Technology, vol. 60, pp. 44-54, 2011.

[25] C. Manzie, H. Watson, and S. Halgamuge, "Fuel economy improvements for urban driving: Hybrid vs. intelligent vehicles," Transportation Research Part C: Emerging Technologies, vol. 15, pp. 1-16, 2007.

[26] P. D. Walker and H. M. Roser, "Energy consumption and cost analysis of hybrid electric powertrain configurations for two wheelers," Applied Energy, vol. 146, pp. 279-287, 2015. 